Check for updates

Cite this: RSC Adv., 2019, 9, 13527

\title{
Direct chemical vapor deposition synthesis of large area single-layer brominated graphene $\uparrow$
}

\author{
Maria Hasan, ${ }^{\text {ag }}$ Wang Meiou, ${ }^{\text {bc }}$ Liu Yulian, ${ }^{\text {bc }}$ Sami Ullah, ${ }^{\text {bc }}$ Huy Q. Ta, ${ }^{\text {bc }}$ Liang Zhao, $^{\text {bc }}$ \\ Rafael G. Mendes, ${ }^{\text {e }}$ Zahida P. Malik, ${ }^{,}$Nasir M. Ahmad, ${ }^{\text {h }}$ Zhongfan Liu (D) ${ }^{a}$ \\ and Mark H. Rümmeli (D)*bcdef
}

Graphene and its derivatives such as functionalized graphene are considered to hold significant promise in numerous applications. Within that context, halogen functionalization is exciting for radical and nucleophilic substitution reactions as well as for the grafting of organic moieties. Historically, the successful covalent doping of $\mathrm{sp}^{2}$ carbon with halogens, such as bromine, was demonstrated with carbon nanotubes. However, the direct synthesis of brominated graphene has thus far remained elusive. In this study we show how large area brominated graphene with $\mathrm{C}-\mathrm{Br}$ bonds can be achieved directly (i.e. a single step) using hydrogen rich low pressure chemical vapor deposition. The direct synthesis of brominated graphene could lead to practical developments.

Received 14th February 2019

Accepted 17th April 2019

DOI: 10.1039/c9ra01152h

rsc.li/rsc-advances precursor for covalent functionalization and as an efficient agent in gas sensing electrodes. ${ }^{7,8}$ Bromine is known to be an efficient leaving group in radical and nucleophilic substitution reactions that well suit grafting organic moieties such as polymer surfaces with $\mathrm{OH}, \mathrm{SH}$ and $\mathrm{NH}_{2}$ functionalities. ${ }^{9}$ The bromine functionalized graphene has been demonstrated to induce properties such as p type doping, ${ }^{10-12}$ oxygen reduction reaction (ORR) activity, ${ }^{13}$ reversible bromine storing, ${ }^{14}$ sulphide ion detection ${ }^{15}$ and electrocatalytic decomposition of $\mathrm{H}_{2} \mathrm{O}_{2}$ in graphene. ${ }^{\mathbf{1 6}}$ Besides, $\mathrm{C}-\mathrm{Br}$ bonds are well suited for efficient grafting of organic moieties on graphene that can be used for various purposes, including electrochemical and electronic devices. ${ }^{17,18}$

However, direct bromine functionalization of pristine graphene is relatively less known, mainly due to the chemically inert nature of pristine graphene. ${ }^{19}$ Moreover, the direct synthesis of $\mathrm{Br}$ doped graphene with $\mathrm{C}-\mathrm{Br}$ bonds (as opposed to adsorbed $\mathrm{Br}_{2}$ ), thus far, has remained elusive. Most production routes for brominated graphene use indirect synthesis approaches and include thermal treatments, ${ }^{12}$ solution-phase synthesis, ${ }^{13}$ chemical bromination ${ }^{14}$ the plasma bromination of graphene, ${ }^{17}$ a halogen atmosphere during exfoliation of graphene oxide, ${ }^{18}$ post treatments of graphite bromide ${ }^{19}$ and CVD synthesized graphene. ${ }^{20}$ However, the indirect and multistep procedures to fabricate $\mathrm{Br}$-doped graphene are time consuming (and thus typically more expensive), low yield and increase the risk of impurities in the final product beside the resultant materials are complex and only coarse control over product stoichiometry is achievable. Thus, there remains a crucial need to develop a facile approach for the direct and large-scale synthesis of Br-doped graphene. This will help pave the way to Technology, Islamabad 44000, Pakistan

$\dagger$ Electronic supplementary information (ESI) available. See DOI: 10.1039/c9ra01152h 
utilize brominated graphene in its various attractive applications at industrial level.

In light of these observations, we felt that it would be of interest to carry out large-area bromination of graphene via facile chemical vapor deposition (CVD) synthesis. The CVD growth of graphene on copper foil is particularly popular due to its distinct advantages such as easy transfer, large scale, and low cost. ${ }^{21}$ The catalytic growth mechanism on $\mathrm{Cu}$ foil surface in the CVD process allows different materials as graphene carbon and dopant source. ${ }^{22}$ We have established the first single-step CVD synthesis route for mono- and few- layer large graphene doped with bound bromine (C-Br bond), as opposed to adsorbed $\mathrm{Br}_{2}$. This was achieved using a single solid precursor of 1,2,5,6,9,10hexabromocyclododecane in $\mathrm{a}_{2}$ rich atmosphere as shown in Fig. 1a.

In our synthesis route, the precursor simultaneously serves as the source of $\mathrm{C}$ and $\mathrm{Br}$. A hydrogen rich environment is chosen since $\mathrm{H}_{2}$ acts as a co-catalyst during the formation of active (surface bound) carbon species $\left(\mathrm{C}_{x} \mathrm{H}_{y}\right)_{z}$ required for efficient growth. In addition, it can etch away weak carbon-carbon bonds. ${ }^{23}$ Parametric studies with precursor zone temperature allow us to optimize for single-layer large area graphene. X-ray photoemission studies confirm the presence of $\mathrm{C}-\mathrm{Br}$ bonding. Thus, our fabrication approach demonstrates the direct synthesis of brominated graphene by CVD is possible.

\section{Materials and methods}

\subsection{Graphene growth}

Bromine doped graphene was synthesized directly on a $25 \mu \mathrm{m}$ thick copper substrate in a horizontal tube furnace at a pressure of 0.5 mbar. 1,2,5,6,9,10-Hexabromocyclododecane (Fig. 1a) was used as the source of both $\mathrm{Br}$ and $\mathrm{C}$ and was purchased from Haihang Industry Co., Ltd. And was used as received. $0.5 \mathrm{mg}$ of this precursor powder was placed upstream (by the closed end of an inner reactor tube). The copper strip $(45 \times 10 \mathrm{~mm})$ was rolled and carefully placed inside the inner reactor tube at a distance of $25 \mathrm{~mm}$ from its open end (opposite end to the precursor). This smaller quartz tube was then placed inside the main CVD furnace quartz tube as shown in Fig. 1b. The system was then evacuated to a pressure of 0.1 mbar with the help of a rotary pump. Afterwards, the system was flushed with pure Ar
(99.99\%) gas at a flow of 200 standard cubic centimeters per minute (SCCM) to reduce residual background gases. The Ar flushing was stopped after 30 minutes and switched to pure $\mathrm{H}_{2}$ (99.99\%) flow at $16 \mathrm{sccm}$ (at a pressure of $0.5 \mathrm{mbar}$ ). The furnace was heated to $1025{ }^{\circ} \mathrm{C}$ in 45 minutes. During heating, the oven remained at the copper foil (substrate) end of the inner quartz tube as indicated by heating position in Fig. 1b. Once the reaction temperature was reached, the CVD oven was slid towards the precursor end indicated by growth position in Fig. $1 \mathrm{~b}$ to obtain the controlled evaporation of the precursor. The explored temperatures for the precursor were 150, 200, 250, 300 and $350{ }^{\circ} \mathrm{C}$, where optimal growth was found at $200{ }^{\circ} \mathrm{C}$ for uniform monolayer graphene. The optimum growth time was 3 minutes. After growth the CVD oven was moved away from the reaction region to provide rapid cooling of the copper substrate and bring the reaction to a rapid stop. ${ }^{24}$ The hydrogen flow was stopped and switched back to $200 \mathrm{sccm}$ of Ar until the furnace had cooled down to room temperature. A detailed graphical representation of the CVD protocol steps are shown in the ESI in Fig. S1. $\dagger$ Moreover, before starting every experiment the inner quartz tube was subsequently washed with acetone, ethanol and deionized water then blow dried with $\mathrm{N}_{2}$. Afterwards it was oxidized at $1025^{\circ} \mathrm{C}$ for 30 minutes in the main CVD quartz tube to remove any source of contamination coming from the tube or the previous experiment.

\subsection{Transfer}

The bromine-doped graphene was transferred on to standard lacey carbon Cu TEM grids for TEM and HRTEM studies. For that purpose, first the copper substrate was spin-coated with a PMMA solution in ethyl acetate, followed by its etching in 0.5 molar aqueous solution of ammonium persulphate (Sigma Aldrich, purity $\geq 98 \%$ ) for $\sim 100$ minutes. Thereafter it was rinsed thoroughly in deionized water. The film was then fished in deionized water onto a standard lacey carbon Cu TEM grid. The PMMA coating was removed in hot acetone vapor. ${ }^{25}$ Finally, to remove any organic residue that might have lifted, the TEM grid was annealed in high vacuum $\left(10^{-6} \mathrm{mbar}\right)$ at $200^{\circ} \mathrm{C}$ for 12 hours. ${ }^{26}$

For SEM and Raman characterizations, instead of a TEM grid $\mathrm{SiO}_{2}(300 \mathrm{~nm}) / \mathrm{Si}$ wafer was used as the substrate for transfer. The wafer was sonicated in pure acetone followed by washing in
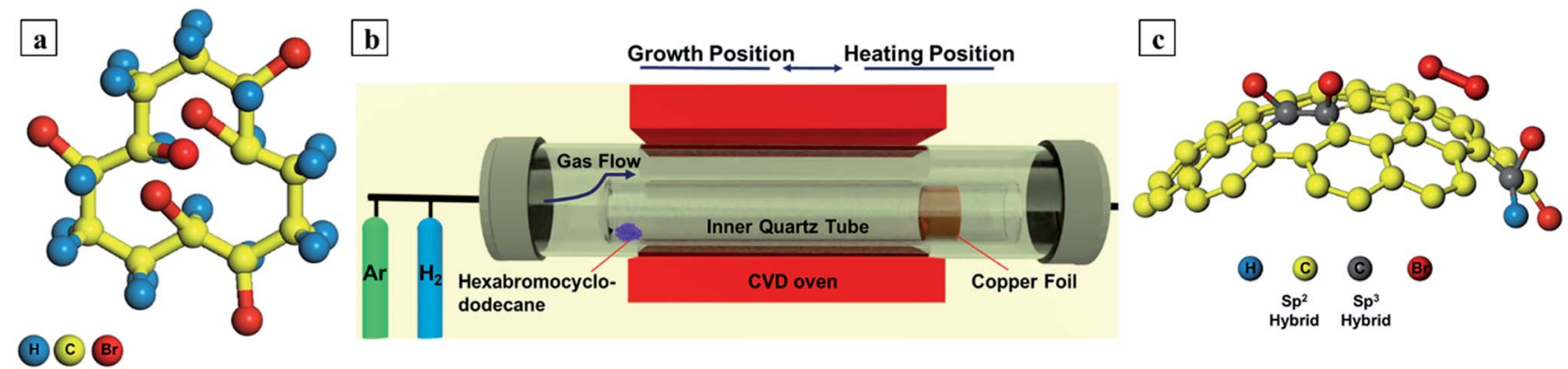

Fig. 1 (a) Precursor (1,2,5,6,9,10-hexabromocyclododecane) stick and ball model (b) CVD set up and protocol (c) stick and ball model showing side view $\mathrm{C}-\mathrm{Br}$ graphene ( $\mathrm{sp}^{3}$-like bonding) and surface adsorbed $\mathrm{Br}_{2}$ (based on ref. 17). 
absolute ethanol and then drying in $\mathrm{N}_{2}$. The graphene film was fished onto it and then annealed in an oven at $75{ }^{\circ} \mathrm{C}$ for 20 minutes. Afterwards, PMMA was removed by dipping it (for 2 minutes) in pure acetone.

\subsection{Characterization}

The large area brominated graphene was characterized through SEM on a Hitachi SU-8010. TEM and HRTEM characterization was performed on a Titan ${ }^{3} 80-300$ with an electron acceleration voltage of $80 \mathrm{kV}$. Raman spectra and mapping were collected on a Horiba (Confocal LabRAM HR 800) using $633 \mathrm{~nm}$ laser while keeping the laser power at $2 \mathrm{~mW}$. XPS was performed on a Thermo Fisher Scientific (model ESCALAB $250 \mathrm{xi}$ ). The FTIR spectrum was recorded in the ATR mode on a Tensor 27 spectrometer from Bruker Optics. The sheet resistance was measured through a SZT-C four-probe test bench Suzhou Jingge electronics.

\section{Results and discussion}

To synthesize our brominated graphene, a CVD reactor setup employing a half closed inner quartz tube configuration (Fig. 1b) was used. The use of the inner quartz tube configuration is helpful in trapping of reaction species that forms on decomposition of the precursor and allows their slow diffusion out of the reactor tube, thus provides sufficient time for graphene formation, in particular for powder precursors. ${ }^{27}$ With this set up even $0.5 \mathrm{mg}$ of precursor material was enough to form large area brominated graphene. However, the rate at which the precursor sublimes and decomposes is affected by the precursor heating rate. Therefore, while the reaction zone (where the $\mathrm{Cu}$ substrate resides) was kept at a constant temperature of $1025{ }^{\circ} \mathrm{C}$, different temperatures at the precursor heating zone were explored to optimize the reaction for the formation of (large area) monolayer brominated graphene. The growth time was maintained at 3 minutes.

Precursor heating zone temperatures from $150{ }^{\circ} \mathrm{C}$ to $350{ }^{\circ} \mathrm{C}$ with $50{ }^{\circ} \mathrm{C}$ steps where explored. In all cases clear modes corresponding to $\mathrm{sp}^{2}$ carbon presence were observed (Fig. 2a-e). These modes are the D peak $\left(\sim 1340 \mathrm{~cm}^{-1}\right)$, the $\mathrm{G}$ peak $\left(\sim 1580 \mathrm{~cm}^{-1}\right)$ and the $2 \mathrm{D}$ mode $\left(\sim 2700 \mathrm{~cm}^{-1}\right)$ but with variation in their relative intensities. ${ }^{28}$ Moreover, for all the samples, the $\mathrm{G}$ band appeared at $1588 \mathrm{~cm}^{-1}$ with a slight upshift of $8 \mathrm{~cm}^{-1}$ and the $2 \mathrm{D}$ band appeared at $2642 \mathrm{~cm}^{-1}$ with a down shift of $58 \mathrm{~cm}^{-1}$ than the usual values concomitant with $\mathrm{Br}$ doping..$^{12,29}$ This is further confirmed by presence of the $\mathrm{D}$ band presence that arise due to defects and doping from $\mathrm{Br}^{29}$

For all precursor heating temperatures, the $2 \mathrm{D}$ peak amplitude intensity is slightly larger than that for the G peak. In addition, the 2D peak is narrow (with a full width at half maximum (FWHM) of $c a .40 \mathrm{~cm}^{-1}$ ) indicating the presence of predominantly monolayer graphene. ${ }^{27}$ As one increases the precursor heating temperature the peaks in the Raman spectra show changes. For the precursor heating temperature of $150{ }^{\circ} \mathrm{C}$ the intensity of the 2D peak is comparatively lower. While measuring the graphene fragments, the signal was weak with large signal to noise ratio suggesting the graphene flakes were inhomogeneous. However, the 2D to G mode and the G to D ratio suggest the fragments are graphene (Fig. S2b †). By acquiring scanning electron micrographs from the samples one can obtain a better impression of the samples to further explain the Raman data. The SEM data in Fig. 2f suggests that when precursor was heated at $150{ }^{\circ} \mathrm{C}$ there was insufficient feedstock of active precursor species and thus continuous graphene layer could not be formed in this case. On increasing the precursor heating temperature further to $200{ }^{\circ} \mathrm{C}$, the intensity of $2 \mathrm{D}$ band become higher and it was more symmetric. FWHM of 2D peak also got lower as compared to that of $150{ }^{\circ} \mathrm{C}$ Fig. S2a. $\dagger$ The corresponding SEM image in Fig. $2 \mathrm{~g}$ shows continuous full coverage graphene. On increasing the precursor heating temperature to $250{ }^{\circ} \mathrm{C}$ the $2 \mathrm{D}$ band of Raman spectrum in Fig. 2c experienced an obvious decrease in its intensity and its FWHM also increased Fig. S2a. $\dagger$ The corresponding SEM image in Fig. $2 \mathrm{~h}$ shows some secondary graphene islands forming over the initial graphene layer. Moreover, the precursor heating temperature at $300{ }^{\circ} \mathrm{C}$ resulted in corresponding increase in FWHM of the 2D peak Fig. S2a $\uparrow$ although the change in $2 \mathrm{D}$ band intensity was negligible. The corresponding SEM image in Fig. 2i showed a regular patched structure of the grown graphene. This indicates that the flakes are becoming larger with rising precursor heating temperature. The Raman and SEM data fit will with each other. The D mode is present in all cases with a G/D of around 5 to 6 Fig. S2b. $\uparrow$ The D mode is attributed to defects, including Br doping. ${ }^{30,31}$ The Raman spectroscopy data with the SEM micrographs shows that the optimum precursor zone temperature is at $c a .200{ }^{\circ} \mathrm{C}$ for large area homogenous single-layer graphene. Additionally a detailed Raman mapping data in Fig. S3. $\dagger$ from brominated single layer graphene was used to investigate the uniformity of the grown graphene. ${ }^{32}$ Raman maps were taken over 30 micrometer square area. The data shows that the brominated graphene is large area and crystalline.

On increasing the temperature further to $350{ }^{\circ} \mathrm{C}$ the corresponding 2D peak in Fig. 2e got wider, shorter and higher in its frequency (appearing at $2660 \mathrm{~cm}^{-1}$ ). ${ }^{28}$ Its FWHM value also increased to $63 \mathrm{~cm}^{-1}$ (Fig. S2a $\dagger$ ) and was no longer symmetric. The $\mathrm{G}$ band also showed a small red shift of $2 \mathrm{~cm}^{-1}$ with the increased number of layers and appeared at $1586 \mathrm{~cm}^{-1} .{ }^{28}$ This indicated a multi-layer graphene formation. The $\mathrm{D}$ peak rose tremendously higher than both $\mathrm{G}$ and $2 \mathrm{D}$ peaks. The result was in agreement with the corresponding SEM image in Fig. $2 \mathrm{j}$ that shows a highly defective graphene. This can be attributed to the anisotropic etching effect of pure $\mathrm{H}_{2}$ that has become more dominant with increased precursor heating temperature. ${ }^{33}$

In case of the single-layer brominated graphene, further characterizations by transmission electron microscopy (TEM) were conducted as shown in Fig. 3. Low magnification studies show uniform large area deposition graphene in Fig. 3a. High resolution TEM (HRTEM) studies show that the graphene formed was predominantly monolayer. This was confirmed by forming holes (through electron beam irradiation) ${ }^{34}$ and visually confirming the layer number, as can be seen, for example, at the top left of Fig. 3b. Higher magnification studies of the 


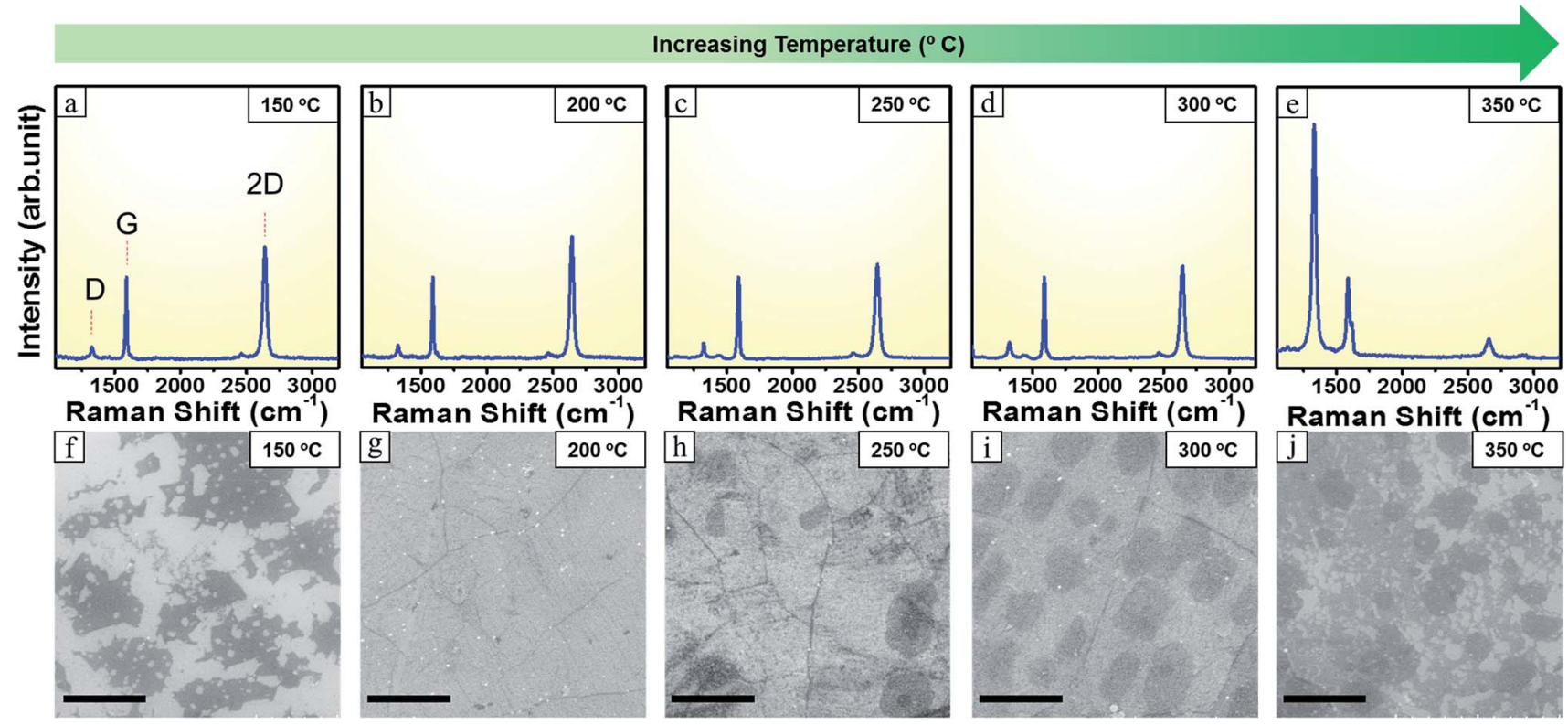

Fig. 2 (a-e) Raman spectra recorded at the different precursor temperature. All spectra normalized w.r.t G mode ( $f-j)$ corresponding SEM images. Scale bar $5 \mu \mathrm{m}$.

material show a nicely crystalline honeycomb lattice concomitant with graphene in Fig. 3c. Moreover, the only one set of six fold symmetric SAED pattern also confirmed the monolayer nature of the brominated graphene in Fig. $3 \mathrm{~d}$ and e..$^{35}$

To better comprehend the nature of the bromine doping in graphene, we conducted core level spectroscopy using X-ray photoemission spectroscopic (XPS). The low resolution long range survey spectrum in Fig. 4a reveals a predominant C 1s peak at $284.3 \mathrm{eV}$ and additional peaks at $257 \mathrm{eV}, 182 \mathrm{eV}, 70.5 \mathrm{eV}$ corresponding to the $\mathrm{Br} 3 \mathrm{~s}, \mathrm{Br} 3 \mathrm{p}, \mathrm{Br} 3 \mathrm{~d}^{36,37}$ In addition, an $\mathrm{O} 1 \mathrm{~s}$ signature at $531 \mathrm{eV}$ and a $\mathrm{Cu} 2 \mathrm{p}$ peaks (at $933 \mathrm{eV}$ ) are observed. ${ }^{36,38}$ The atomic percentage of $\mathrm{Br}$ is $c a .3 .5 \%$ while that for $\mathrm{C}$ is $49.7 \%$. The $\mathrm{O}$ and $\mathrm{Cu}$ contributions, which are attributed to the substrate are $4.3 \%$ and $41.8 \%$, respectively. ${ }^{39,40}$ The high resolution $\mathrm{C} 1 \mathrm{~s}$ main peak in Fig. $4 \mathrm{~b}$ can be fitted into three components centered at $284.3 \mathrm{eV}, 285.1 \mathrm{eV}$ and $286.5 \mathrm{eV}$ that can be ascribed to $\mathrm{C}=\mathrm{C}, \mathrm{C}-\mathrm{C} / \mathrm{C}-\mathrm{H}$ and $\mathrm{C}-\mathrm{O} / \mathrm{C}-\mathrm{Br}$ respectively. ${ }^{36}$ The relative percentages of each of these three peaks are $43.7 \%$, $25.9 \%$ and $30 \%$ respectively. The larges fraction is due to $\mathrm{sp}^{2} \mathrm{C}$ (graphene), the second to a more $\mathrm{sp}^{3}$-like fraction with $\mathrm{C} / \mathrm{H}$ and the lowest fraction due to $\mathrm{C}-\mathrm{Br}^{29}$

Furthermore, to show unequivocally that there is a $\mathrm{C}-\mathrm{Br}$ fraction, we look in more detail at the Br 3d XPS response from bromine in Fig. 4c. Similar to previous studies on brominated CNTs two peak pairs are of observed here due to the different types of bromine bonds. ${ }^{29} \mathrm{~A}$ very weak doublet at the lower energies of $64.3 \mathrm{eV}$ and $65.4 \mathrm{eV}$ corresponds $\mathrm{Br} 3 \mathrm{~d}_{5 / 2}$ lines. The doublet at higher energy with edges at $69.9 \mathrm{eV}$ and $72.3 \mathrm{eV}$ corresponds to $\mathrm{Br} 3 \mathrm{~d}_{3 / 2}$ lines. ${ }^{29}$ Among each set of the doublet pairs the low lying peaks at $64.3 \pm 0.2$ and $69.9 \pm 0.2$ are assumed to arise from the physically adsorbed bromine derivatives such as carbon charge transfer $\mathrm{Br}_{2}$ complexes and $\mathrm{BrH}^{41}$ Due to covalent bond formation between $\mathrm{C}$ and $\mathrm{Br}$, a more stable and stronger interaction occurs and the high energy components at $65.4 \pm 0.2$ and $72.3 \pm 0.2$ is assigned to $\mathrm{C}-\mathrm{Br}$ bond that confirms the formation of brominated graphene. ${ }^{29,42,43}$ The $\mathrm{C}-\mathrm{Br}$ content was determined as $1.8 \%$ while the $\mathrm{Br}_{2}$ content is $c a .2 \%$ (error $\pm 0.1 \%$ ). The XPS data confirms
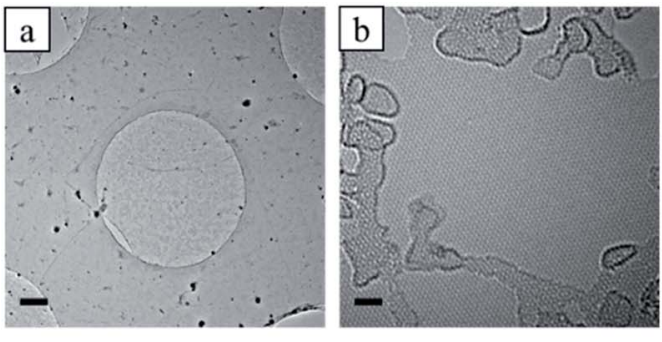
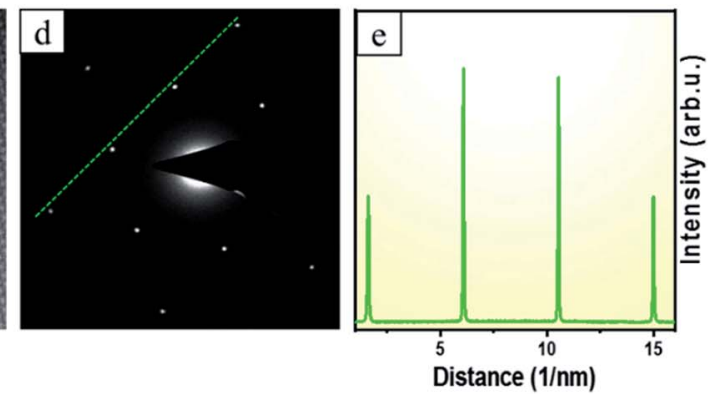

Fig. 3 (a) TEM image shows large area deposition of the Br doped graphene. Scale bar $2 \mu \mathrm{m}$ ( $\mathrm{b}$ and $\mathrm{c}$ ) HRTEM images showing the Br doped graphene is single layer. Scale bar $1 \mathrm{~nm}$ ( $d$ and e) SAED data and intensity profiles over the $\{1010\}$ and outer $\{1120\}$ reflexes showing the formed graphene is monolayer. The dark pointer in (d) is the shadow of the beam stop used to block the intense direct beam. 

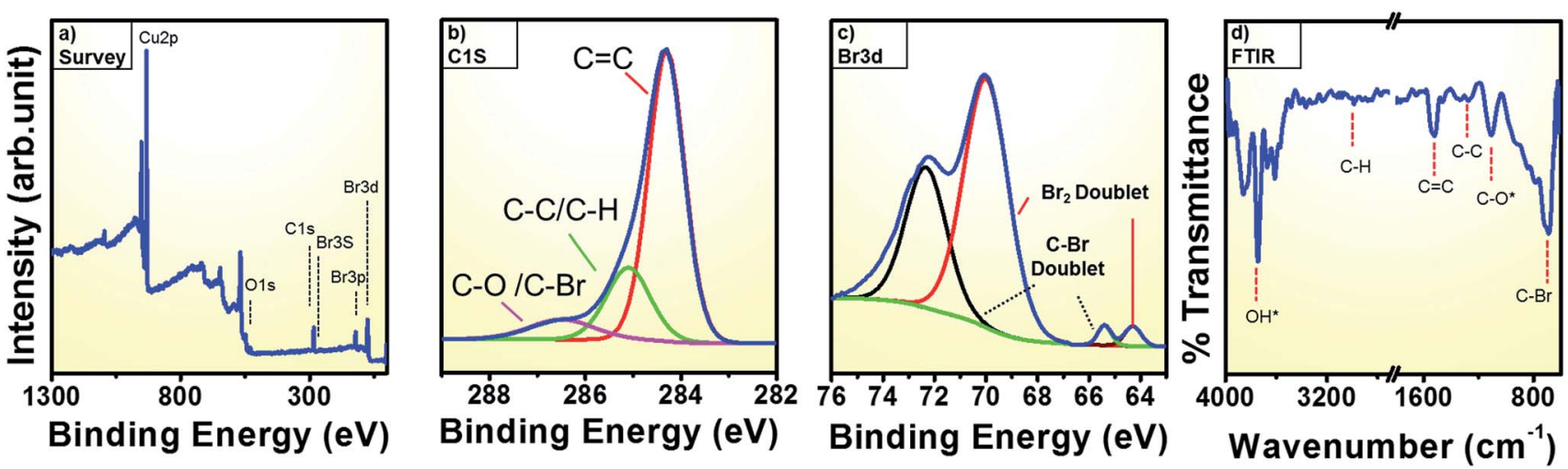

Fig. 4 (a) Long range XPS survey spectrum for optimized precursor heating at $200^{\circ} \mathrm{C}$ (b) high resolution $\mathrm{C} 1 \mathrm{~s}$ spectrum (c) high resolution $\mathrm{Br} 3 \mathrm{~d}$ spectrum (d) ATR spectrum in transmission mode. Adsorptions in ambient labelled with *

the presence of a $\mathrm{C}-\mathrm{Br}$ bond in the graphene. Indeed, the electrophilic addition of bromine across the graphene double bond changes the $\mathrm{sp}^{2}$ hybrid character to a more $\mathrm{sp}^{3}$-like geometry. ${ }^{17}$

We also examined the $\mathrm{Cu}$ data. The $\mathrm{Cu} 2 \mathrm{p}$ spectrum in Fig. S4a† from the $\mathrm{Cu}$ substrate shows the presence of shake up bands suggest there may be a little oxidized $\mathrm{Cu}$ (due to defects (e.g. grain boundaries or perhaps the bromination sites))..$^{38}$ To better comprehend this we look at the $\mathrm{O} 1 \mathrm{~s}$ spectrum (Fig. S4b†), which show two peaks at $529.8 \mathrm{eV}$ and $531 \mathrm{eV}$ can be attributed to $\mathrm{Cu}_{2} \mathrm{O} / \mathrm{CuO}$ and $\mathrm{C}-\mathrm{O}$ respectively. ${ }^{39,44}$ The respective atomic percentages for $\mathrm{C}-\mathrm{O}$ and $\mathrm{Cu}_{2} \mathrm{O} / \mathrm{CuO}$ are $c a .2 .5 \%$ and $2.4 \%$. This indicates that a small fraction of the brominated graphene is also oxidized. It is unclear if this occurs at defects sites after exposure to air or during synthesis..$^{39,42}$

We additionally look at the functional groups of the brominated graphene with FTIR. In the FTIR spectrum (Fig. 4d) the peaks at $\sim 1250 \mathrm{~cm}^{-1}$ and $\sim 1100$ can be attributed to $\mathrm{C}-\mathrm{C}$ and $\mathrm{C}-\mathrm{O}$ vibrations, respectively. ${ }^{45}$ The peak at $c a .1530 \mathrm{~cm}^{-1}$ is due to the $\mathrm{C}=\mathrm{C}$ stretching mode and appears as a strong peak. ${ }^{45,46}$ An intense peak at $690 \mathrm{~cm}^{-1}$ is attributed to $\mathrm{C}-\mathrm{Br}$ and further supports the formation of brominated graphene., ${ }^{8,45,46}$ The absorption in the region from 3600 to $3700 \mathrm{~cm}^{-1}$ is due to surface adsorbed $\mathrm{OH}$ species from the ambient. ${ }^{46}$ The absorption due to $\mathrm{C}-\mathrm{H}$ bond is assigned at $2987 \mathrm{~cm}^{-1}$. $^{46}$ Thus, the XPS and FTIR data all confirm presence of covalently bonded Br. The FTIR data correlate very well with the XPS results.

Finally, we also examined the sheet resistance of the brominated graphene sheets, produced under different precursor heating temperature, using the four probe sheet resistance method. (Fig. S2c $\dagger$ ) For the precursor heating temperature of $150{ }^{\circ} \mathrm{C}$ the sheet resistance cannot be measured due to absence of any continuous layer formation at this temperature. For the precursor heating temperatures of 200,250 and $300{ }^{\circ} \mathrm{C}$, the corresponding sheet resistance increased with increasing temperature. This can be correlated with SEM data where increasing the temperature led to the formation of additional secondary graphene layers as islands over the initial large area graphene. These additional islands provide scattering sties that thereby increase in the sheet resistance. ${ }^{47,48}$

\section{Conclusions}

In summary, we have developed the first direct, scalable and simple single step CVD process for large area, single layer, crystalline graphene with covalently doped bromine. We achieve this by using 1,2,5,6,9,10-hexabromocyclododecane as the powder precursor for $\mathrm{Br}$ and $\mathrm{C}$ species in a hydrogen rich environment. Indeed, this is the first report to show that direct synthesis of brominated graphene through CVD is possible. Moreover, the single solid precursor that acts as the elemental feedstock for both $\mathrm{C}$ and $\mathrm{Br}$ yields crystalline, large area and monolayer brominated graphene. The successful direct facile single step formation of brominated graphene by CVD thus offers a scalable pathway for the synthesis of a versatile spectrum of graphene derivatives suitable for a range of potential applications. ${ }^{14}$

\section{Conflicts of interest}

There are no conflicts to declare.

\section{Acknowledgements}

This work is supported by the National Science Foundation China (NSFC, Project 51672181), the National Science Center, Poland for the financial support within the frame of the Opus program (Grant agreement 2015/19/B/ST5/03399), the Czech Republic from ERDF "Institute of Environmental Technology Excellent Research" (No. CZ.02.1.01/0.0/0.0/15_019/0000853). MHR thanks the Sino-German Research Institute for support (project: GZ 1400) and the start-up funding of the Suzhou Institute for Energy and Materials innovations (SIEMIS) and the School of Energy, Suzhou University.

\section{References}

1 K. S. Novoselov, A. K. Geim, S. V. Morozov, D. Jiang, M. I. Katsnelson, I. V. Grigorieva, S. V. Dubonos and A. A. Firsov, Nature, 2005, 438, 197-200.

2 A. J. Marsden, P. Brommer, J. J. Mudd, M. A. Dyson, R. Cook, M. Asensio, J. Avila, A. Levy, J. Sloan, D. Quigley, G. R. Bell and N. R. Wilson, Nano Res., 2015, 8(8), 2620-2635. 
3 D. W. Boukhvalov and M. I. Katsnelson, J. Phys.: Condens. Matter, 2009, 21(34), 344205.

4 D. R. Dreyer, A. D. Todd and C. W. Bielawski, Chem. Soc. Rev., 2014, 43, 5288-5301.

5 R. S. Lee, H. J. Kim, J. E. Fischer and A. Thess, Nature, 1997, 388, 255-257.

6 E. Unger, A. Graham, F. Kreupl, M. Liebau and W. Hoenlein, Curr. Appl. Phys., 2002, 2, 107-111.

7 F. Hof, F. Hauke and A. Hirsch, Chem. Commun., 2014, 50, 6582-6584.

8 D. Hines, M. H. Rummeli, D. Adebimpe and D. L. Akins, Chem. Commun., 2014, 50, 11568-11571.

9 S. Wettmarshausen, G. Kuhn, G. Hidde, H. U. Mittmann and J. F. Friedrich, Plasma Processes Polym., 2007, 4, 832-839.

10 X. Fan, L. Liu, J.-L. Kuo and Z. Shen, J. Phys. Chem. C, 2010, 114, 14939-14945.

11 N. Jung, N. Kim, S. Jockusch, N. J. Turro, P. Kim and L. Brus, Nano Lett., 2009, 9, 4133-4137.

12 S. W. Chu, S. J. Baek, D. C. Kim, S. Seo, J. S. Kim and Y. W. Park, Synth. Met., 2012, 162, 1689-1693.

13 K. H. Wu, D. W. Wang, Q. Zeng, Y. Li and I. R. Gentle, Chin. J. Catal., 2014, 35, 884-890.

14 O. Jankovsky, P. Simek, K. Klimova, D. Sedmidubsky, S. Matejkova, M. Pumera and Z. Sofer, Nanoscale, 2014, 6, 6065-6074.

15 S. Singh, K. Mitra, A. Shukla, R. Singh, R. K. Gundampati, N. Misra, P. Maiti and B. Ray, Anal. Chem., 2017, 89, 783-791.

16 S. Singh, M. Singh, K. Mitra, R. Singh, S. K. S. Gupta, I. Tiwari and B. Ray, Electrochim. Acta, 2017, 258, 1435-1444.

17 J. F. Friedrich, G. Hidde, A. Lippitz and W. E. S. Unger, Plasma Processes Polym., 2014, 34, 621-645.

18 H. L. Poh, P. Simek, Z. Sofer and M. Pumera, Chem.-Eur. J., 2013, 19, 2655-2662.

19 J. Zheng, H.-T. Liu, B. Wu, C.-A. Di, Y.-L. Guo, T. Wu, G. Yu, Y.-Q. Liu and D.-B. Zhu, Sci. Rep., 2012, 2, 662.

20 A. E. Mansour, S. Dey and A. Amassian, ACS Appl. Mater. Interfaces, 2015, 7, 17692-17699.

21 X. Li, W. Cai, J. An, S. Kim, J. Nah, D. Yang, R. Piner, A. Velamakanni, I. Jung, E. Tutuc, S. K. Banerjee, L. Colombo and R. S. Ruoff, Science, 2009, 324, 1312-1314.

22 H. Wang, Y. Zhou, D. Wu, L. Liao, S. Zhao, H. Peng and Z. Liu, Small, 2013, 9(8), 1316-1320.

23 I. Vlassiouk, M. Regmi, P. Fulvio, S. Dai, P. Datskos, G. Eres and S. Smirnov, ACS Nano, 2011, 5, 6069-6076.

24 J. Seo, J. Lee, A. R. Jang, Y. Choi, U. Kim, H. S. Shin and H. Park, Chem. Mater., 2017, 29, 4202-4208.

25 H. Q. Ta, D. J. Perello, D. L. Duong, G. H. Han, S. Gorantla, V. L. Nguyen, A. Bachmatiuk, S. V. Rotkin, Y. H. Lee and M. H. Rümmeli, Nano Lett., 2016, 16, 6403-6410.

26 S. Gorantla, A. Bachmatiuk, J. Hwang, H. A. Alsalman, J. Y. Kwak, T. Seyller, J. Eckert, M. G. Spencere and M. H. Rummeli, Nanoscale, 2014, 6, 889-896.

27 M. H. Rümmeli, S. Gorantla, A. Bachmatiuk, J. Phieler, N. Geißler, I. Ibrahim, J. Pang and J. Eckert, Chem. Mater., 2013, 25, 4861-4866.
28 I. Childres, L. A. Jauregui, W. Park, H. Cao and Y. P. Chen, New Developments in Photon and Materials Research, Nova Science Publishers, Hauppauge NY, 2013.

29 L. G. Bulusheva, A. V. Okotrub, E. Flahaut, I. P. Asanov, N. P. Gevko, V. O. Koroteev, Yu. V. Fedoseeva, A. Yaya and C. P. Ewels, Chem. Mater., 2012, 24, 2708-2715.

30 M. H. Rummeli, A. Bachmatiuk, A. Scott, F. Borrnert, J. H. Warner, V. Hoffman, J. H. Lin, G. Cuniberti and B. Buchner, ACS Nano, 2010, 4, 4206-4210.

31 J. F. Friedrich, S. Wettmarshausen, S. Hanelt, R. Mach, R. Mix, E. B. Zeynalov and A. Meyer-Plath, Carbon, 2010, 48, 3884-3894.

32 E. Auchter, J. Marquez, S. L. Yarbro and E. Dervishi, AIP Adv., 2017, 7, 125306.

33 Y. Zhang, Z. Li, P. Kim, L. Zhang and C. Zhou, Anisotropic Hydrogen Etching of Chemical Vapor Deposited Graphene, ACS Nano, 2012, 6(1), 126-132.

34 L. Zhao, H. Q. Ta, A. Dianat, A. Soni, A. Fediai, W. Yin, T. Gemming, B. Trzebicka, G. Cuniberti, Z. Liu, A. Bachmatiuk and M. H. Rummeli, Nano Lett., 2017, 17, 4725-4732.

35 Q. Yu, L. A. Jauregui, W. Wu, R. Colby, J. Tian, Z. Su, H. Cao, Z. Liu, D. Pandey, D. Wei, T. F. Chung, P. Peng, N. P. Guisinger, E. A. Stach, J. Bao, S. S. Pei and Y. P. Chen, Nat. Mater., 2011, 10, 443-449.

36 J. F. Colomer, R. Marega, H. Traboulsi, M. Meneghetti, G. V. Tendeloo and D. Bonifazi, Chem. Mater., 2009, 21, 4747-4749.

37 J. Gao, F. Bao, Q. Zhu, Z. Tan, T. Chen, H. Cai, C. Zhao, Q. Cheng, Y. Yanga and R. Ma, Polym. Chem., 2013, 4, 1672-1679.

38 V. Hayez, A. Franquet, A. Hubin and H. Terryn, Surf. Interface Anal., 2004, 36, 876-879.

39 J. Kwak, Y. Jo, S. D. Park, N. Y. Kim, S. Y. Kim, H. J. Shin, Z. Lee, S. Y. Kim and S. Y. Kwon, Nat. Commun., 2017, 8, 1-12.

40 P. R. Kidambi, B. C. Bayer, R. Blume, Z. J. Wang, C. Baehtz, R. S. Weatherup, M. G. Willinger, R. Schloegl and S. Hofmann, Nano Lett., 2013, 13, 4769-4778.

41 E. Papirer, R. Lacroix, J.-B. Donnet, G. Nanse and P. Fioux, Carbon, 1994, 32, 1341.

42 H. Au, N. Rubio and M. S. P. Shaffer, Chem. Sci., 2018, 9, 209217.

43 Y. Li, H. Chen, L. Y. Voo, J. Ji, G. Zhang, G. Zhang, F. Zhang and X. Fan, J. Mater. Chem., 2012, 22, 15021-15024.

44 J. Zhang, C. Li, Z. Peng, Y. Liu, J. Zhang, Z. Liu and D. Li, Sci. Rep., 2017, 7, 4886.

$45 \mathrm{~J}$. Coates and R. A. Meyers, Encyclopedia of Analytical Chemistry, John Wiley \& Sons Ltd., Chichester, 2000.

46 Z. Xiaorong, L. Yanan, T. Chengan, Z. Hui, X. Lin and W. Jianfang, Mater. Res. Express, 2017, 4, 045601.

47 F. Banhart, J. Kotakoski and A. V. Krasheninnikov, ACS Nano, 2010, 5, 26-41.

48 T. O. Wehling, S. Yuan, A. I. Lichtenstein, A. K. Geim and M. I. Katsnelson, Phys. Rev. Lett., 2010, 105, 056802. 